\title{
EPR, UV-Visible, and Near-Infrared Spectroscopic Characterization of Dolomite
}

\author{
S. Lakshmi Reddy, ${ }^{1}$ R. L. Frost, ${ }^{2}$ G. Sowjanya, ${ }^{1}$ N. C. G. Reddy, ${ }^{3}$ \\ G. Siva Reddy, ${ }^{3}$ and B. J. Reddy ${ }^{2}$ \\ ${ }^{1}$ Department of Physics, S.V.D. College, Kadapa 516003, India \\ ${ }^{2}$ Inorganic Materials Research Program, Queensland University of Technology, 2 George Street, Brisbane, \\ GPO Box 2434, Queensland 4001, Australia \\ ${ }^{3}$ Department of Chemistry, Yogi Vemana University, Kadapa 516003, India
}

Correspondence should be addressed to R. L. Frost, r.frost@qut.edu.au

Received 17 June 2008; Accepted 21 October 2008

Recommended by David Huber

Dolomite mineral samples having white and light green colors of Indian origin have been characterized by EPR, optical, and NIR spectroscopy. The optical spectrum exhibits a number of electronic bands due to presence of Fe(III) ions in the mineral. From EPR studies, the parameters of $g$ for $\mathrm{Fe}$ (III) and $g, A$, and $D$ for $\mathrm{Mn}$ (II) are evaluated and the data confirm that the ions are in distorted octahedron. Optical absorption studies reveal that Fe(III) is in distorted octahedron. The bands in NIR spectra are due to the overtones and combinations of water molecules. Thus EPR and optical absorption spectral studies have proven useful for the study of the solid state chemistry of dolomite.

Copyright (C) 2008 S. Lakshmi Reddy et al. This is an open access article distributed under the Creative Commons Attribution License, which permits unrestricted use, distribution, and reproduction in any medium, provided the original work is properly cited.

\section{Introduction}

Carbonate minerals in various forms such as limestone, dolomite, and calcite constitute the earth's largest $\mathrm{CO}_{2}$ resource. The dolomite group of minerals have the general formula $\mathrm{A}^{++} \mathrm{B}^{++}\left(\mathrm{CO}_{3}\right)_{2}$. When large amount of iron is present, the mineral ankerite forms and when excess manganese is present the mineral kuntnohorite forms instead of dolomite. All these minerals have the same internal structure but differ chemically from each other [1]. This group of minerals is classified [2] into several types as given below:

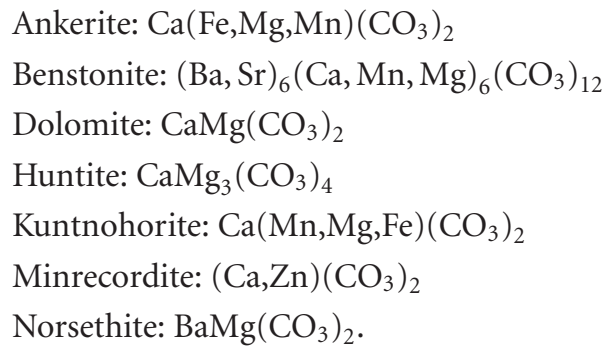

In the above group of minerals, $\mathrm{Mg}$ (II) can be replaced by ferrous iron and manganese. In dolomites the $\mathrm{Mn}$ (II) ion is a natural substitutional impurity at the sites of both $\mathrm{Ca}(\mathrm{II})$ and $\mathrm{Mg}(\mathrm{II})$ ions. Composition of low-Mn ankerite generally approached the formula $\mathrm{CaMg}\left(\mathrm{CO}_{3}\right)_{2}-\mathrm{CaFe}\left(\mathrm{CO}_{3}\right)_{2}$ [3]. This group of minerals has the wide useful applications especially as fillers some of which are given below:

(i) in cement paints, exterior paints, primers, putties, powder coatings, and industrial finishes;

(ii) in PVC footwear, PVC pipes, cables, and others;

(iii) in paper to give smoothness and gloss;

(iv) in adhesives and carpet backing;

(v) in toothpaste, cosmetic, and soap industry.

Dolomites are isostructural having space group $R_{3}$. Dolomite structure reveals that there are two distinct cation sites denoted by A and B [4]. These both sites form nearly regular octahedra in which each corner of an octahedron is oxygen from a different $\mathrm{CO}_{3}$ group. The site $\mathrm{A}$ is occupied by $\mathrm{Ca}$ and the $\mathrm{B}$ site is occupied by $\mathrm{Mg}$ in the ideally ordered case with layers of $\mathrm{Ca}$ octahedron alternating with layers of $(\mathrm{Mg}, \mathrm{Fe}, \mathrm{Mn})$ octahedron. The octahedra are linked 
TABLe 1: Chemical composition of dolomite.

\begin{tabular}{lccc}
\hline Component & \multicolumn{3}{c}{ Percentage } \\
& 1 & 2 & 3 \\
(green) & (white) & (pale yellow) \\
\hline $\mathrm{CaCO}_{3}$ & 53.6 & 56.6 & \\
$\mathrm{MgCO}_{3}$ & 42.0 & 43.0 & 31.27 \\
$\mathrm{CaO}$ & 31.7 & 31.7 & 21.12 \\
$\mathrm{MgO}$ & 20.5 & 20.5 & \\
$\mathrm{Fe}_{2} \mathrm{O}_{3}$ & 0.30 & 0.30 & 0.12 \\
$\mathrm{SiO}_{2}$ & 5.50 & 1.50 & 0.22 \\
$\mathrm{Al}_{2} \mathrm{O}_{3}$ & 0.50 & 0.50 & \\
$\mathrm{FeO}$ & & & \\
\hline
\end{tabular}

1: The Good Earth Udaipur, Rajasthan, India; 2: Famous Minerals \& Chemicals Private Limited; 3: Haley, Ontario, Canada, Mineral data publishing version I, 2001-2005.

by sharing corners simultaneously with octahedra of the opposite kind with $\mathrm{CO}_{3}$ groups [4]. The two octahedra in dolomite are trigonally distorted by elongation along the three-fold axis. The larger A octahedron is always slightly more distorted than that in B $[4,5]$. Detailed spectral studies have been reported on dolomite-ankerite series but not on dolomite of Indian origin [3,6-8]. Several studies have been made on natural dolomites from different origins using EPR studies [9-11]. However, few EPR studies have been done which could identify paramagnetic radicals in dolomites around $g=2.0023$ [11]. Nevertheless, complete interpretation of the EPR spectra of dolomites is not available. Hence, optical absorption and EPR studies on some natural carbonate minerals have been made [12].

Transition metal ions such as $\mathrm{Fe}(\mathrm{III}), \mathrm{Mn}(\mathrm{II})$, and V(IV) display a rich coordination in minerals. For the identification and characterization of these metal ions in natural systems, electron paramagnetic resonance has been found to be the most powerful analytical technique. In India, Kadapa Basin is endowed with rich mineral resources. In this paper, we report the EPR and optical absorption spectral studies of dolomites obtained from Vempalli Mandal of Kadapa district, Andhra Pradesh, India.

\section{Theory}

Several EPR parameters (i.e., $g, A, D$, and $E$ ) are used while interpreting EPR data. The $g$ parameter is a measure of the coupling between the unpaired electron's spin angular momentum $(S)$ and its orbital angular momentum $(L)$ [13].

The unpaired electron interacts (couples) with the nuclear spin $(I)$ to form a $(2 I+1)$ line hyperfine structure centered on $g$ and spaced with the distance quantified by the hyperfine coupling parameter $A$. The coupling between the nuclear and electron spins becomes stronger as the $A$ parameter becomes larger. The combinationof $g$ and $A$ parameters can be utilized to differentiate between electron environments of $\mathrm{Fe}^{3+}$ and $\mathrm{Mn}^{2+}$ ions. The EPR zero field splitting (ZFS) parameters $D$ and $E$ measure the deviation of the ion crystal field from ideal tetrahedralor octahedral symmetries and they apply to ions with more than one unpaired electron (e.g., low field $\mathrm{Fe}^{3+}$ and $\mathrm{Mn}^{2+}$ ). However, the broad nature of EPR spectra of $\mathrm{Fe}^{3+}$ makes the determination of $D$ and $E$ difficult [14].

$\mathrm{Mn}(\mathrm{II})$, being a $\mathrm{d}^{5}$ ion, has total spin $S=5 / 2$. This state splits into three Kramers' doublets, $\pm 5 / 2>, \pm 3 / 2>$, and $\pm 1 / 2>$ separated by $4 D$ and $2 D$, respectively, where $D$ is the zero-field splitting parameter. The deviation from axial symmetry leads to a term known as $E$ in the spin Hamiltonian. The value of $E$ can be easily calculated from single crystal measurements. A nonzero value of $E$ results in making the spectrum unsymmetrical about the central sextet.

\section{Results and Discussion}

\subsection{Total Chemical Analyses}

Dolomite minerals examined in this study are ankerite and dolomite. Elemental compositions of metal are listed in Table 1 [15-17].

\subsection{EPR Spectral Analysis}

EPR spectrum of the dolomite mineral samples recorded at room temperature is given in Figures 1(a) and 1(b). The overall EPR spectral features are similar in both dolomites. It is well known that the EPR studies of transition metal ion $\mathrm{Mn}(\mathrm{II})$ is easily observed at room temperature, even if present in minute levels, compared to other ions. Both spectra (Figures 1(a) and 1(b)) clearly indicate the presence of $\mathrm{Mn}(\mathrm{II})$ in the sample. An expanded version of central sextet is shown in Figures 2(a) and 2(b).

Figures $1(\mathrm{a})$ and $1(\mathrm{~b})$ contain a strong sextet at the centre of the spectrum corresponding to the electron spin transition $+1 / 2>$ to $-1 / 2>$. Generally, in most of the cases, the powder spectrum is characterized by a sextet, corresponding to this transition. The other four transitions, corresponding to $\pm 5 / 2>\leftrightarrow \pm 3 / 2>$ and $\pm 3 / 2>\leftrightarrow \pm 1 / 2>$ are not seen due to their high anisotropy in $D$. If $E \neq 0$, the EPR spectrum will not be symmetrical about the central sextet. The expanded version of the powder spectrum (Figures 2(a) and 2(b)) of both dolomite mineral samples indicate the presence of at least four types of $\mathrm{Mn}$ (II) impurities in the mineral. The sixth manganese hyperfine resonance clearly contains two lines (marked by a and b). This is also followed by two more sets of weak lines (marked by $*$ and $* *$ ) on either side of the intense Mn(II) signals as shown in Figures 2(a) and 2(b). This is the same in both samples. This is due to the presence of $\mathrm{Mn}$ (II) ions in a low symmetry environment [18]. The EPR line intensity of $\mathrm{Mn}$ (II) hyperfine lines observed in green dolomite is more intense, when compared to that in the white dolomite mineral. This indicates clearly that the concentration of $\mathrm{Mn}(\mathrm{II})$ ions in green dolomite sample is more than that in the white dolomite. Even when viewed with a naked eye, the sample is pale greenish pink in color indicating the substitution of manganese ion in larger concentration in this mineral. 


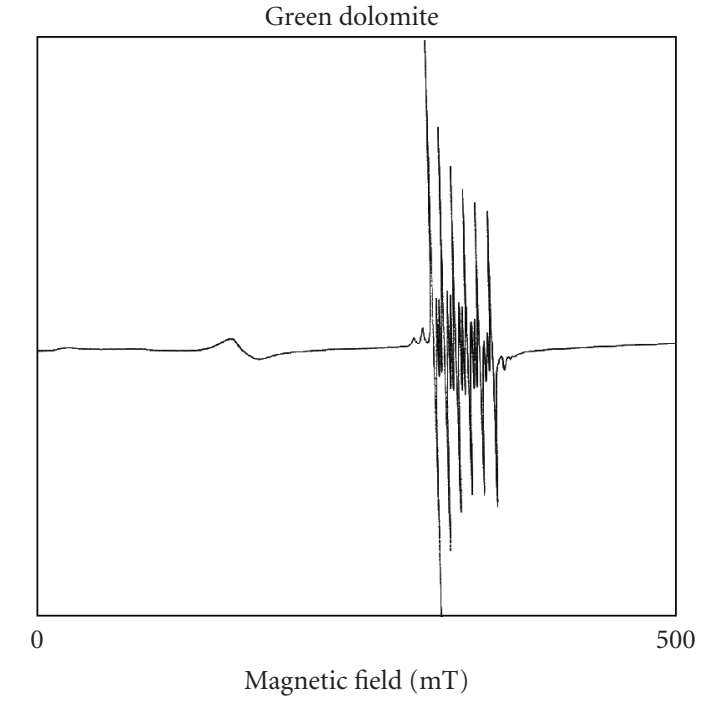

(a)

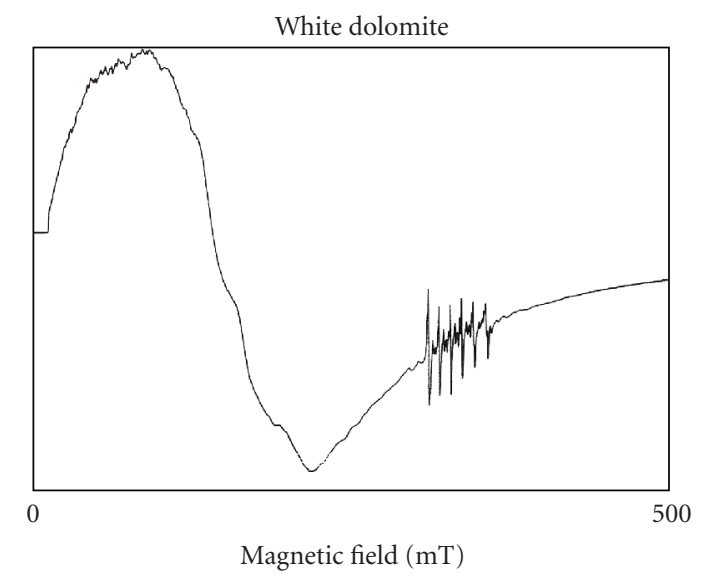

(b)

FIgURE 1: (a) EPR spectrum of green dolomite at RT $(v=$ $9.39219 \mathrm{GHz})$. (b) EPR spectrum of white dolomite at RT $(v=$ $9.39208 \mathrm{GHz})$.

The observed EPR spectrum can be explained by the spin-Hamiltonian of the form as shown in the following equation (see [19]):

$$
H=\beta B g S+D\left\{S_{Z}^{2}-\frac{1}{3} S(S+I)\right\}+S A I
$$

Here the first term represents the electron-Zeeman interaction. The second term represents the zero field contribution, and the third term represents the nuclear-Zeeman interaction. The extra set of resonances in between the main sextet is due to the forbidden transitions. From the forbidden doublet lines, the Zero field splitting parameter, $D$, has been calculated using the formula (see $[20,21]$ )

$$
\Delta H=\left(\frac{2 D^{2}}{H_{m}}\right)\left[\frac{1+16\left(H_{m}-8 A m\right)^{2}}{9 H_{i} H_{m}-64 A m}\right] .
$$

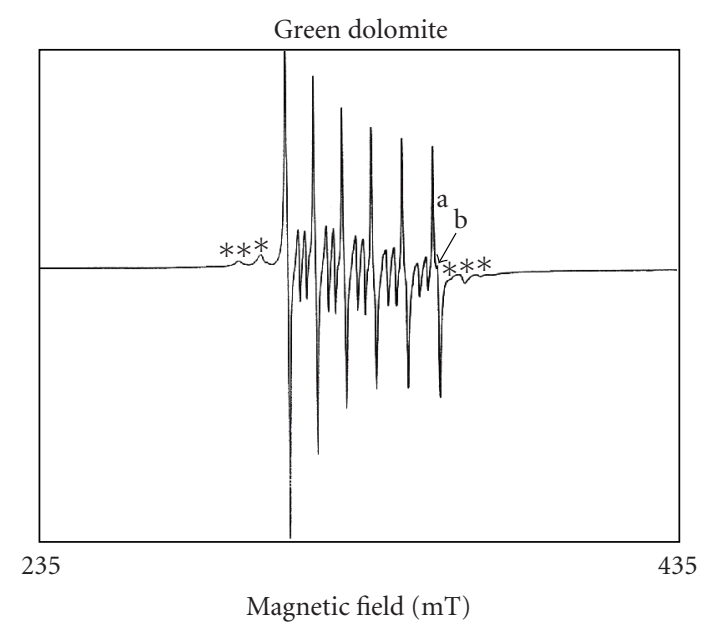

(a)

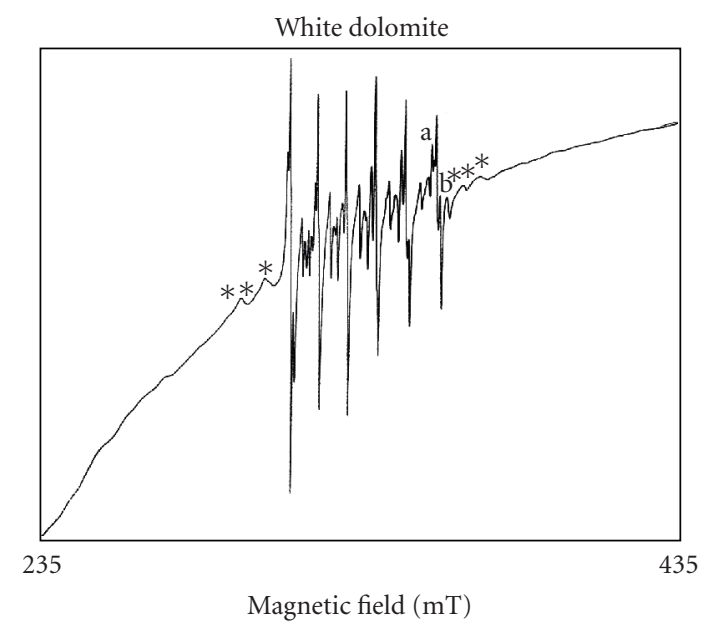

(b)

Figure 2: (a) Expanded form of EPR spectrum of green dolomite at RT $(v=9.39128 \mathrm{GHz})$. (b) Expanded form of EPR spectrum of white dolomite at RT $(v=9.39183 \mathrm{GHz})$.

Here

$$
H_{m}=H_{o}-A m-\frac{\left[I(I+1)-m^{2}\right] A^{2}}{2 H_{o}} .
$$

From the powder spectrum of the mineral, the following parameters have been calculated:

White dolomite

$$
\begin{gathered}
g=1.992 \pm 0.015, \quad A=9.15 \pm 0.43 \mathrm{mT} \\
D=34.45 \pm 0.36 \mathrm{mT} .
\end{gathered}
$$

Green dolomite

$$
\begin{gathered}
g=1.993 \pm 0.017, \quad A=9.35 \pm 0.43 \mathrm{mT}, \\
D=34.25 \pm 0.35 \mathrm{mT}
\end{gathered}
$$

The observed $g, A$, and $D$ values are comparable with other similar systems and agree well within the experimental 
error $[8,22-25]$. The large value of $D$ indicates a considerable amount of distortion around the central metal ion. As EPR is highly sensitive to $\mathrm{Mn}$ (II) impurity, four such sites have been noticed in the EPR spectrum. A close look at the EPR spectrum indicates a nonzero value for $E$, which is very difficult to estimate from powder spectrum. A close look at the centre of the EPR spectrum indicates a broad line underneath the $\mathrm{Mn}(\mathrm{II})$ sextet. This can be attributed to the iron impurity in the sample. Generally, Fe(III) and $\mathrm{Fe}(\mathrm{II})$ impurities will give rise to a broad line around with a $g$ value of 2. No extra information can be obtained from the powder spectrum recorded at room temperature and low temperature except that iron is present as an impurity. Even though the percentage of iron is more than that of manganese, its intensity is relatively smaller compared to the signals obtained from the manganese impurity. The EPR spectrum of white dolomite exhibits a broad resonance centered when $g$ is 4.20 ; similarly a weak resonance is observed when $g$ is 4.34 in the case of green dolomite. Those are attributed to the presence of isolated Fe(III) ions incorporated as an impurity in the mineral.

The hyperfine constant " $A$ " value provides a qualitative measure of the ionic nature of bonding with $\mathrm{Mn}$ (II) ion. The percentage of covalency of Mn-ligand bond in green dolomite has been calculated using " $A$ " (9.35 mT) value obtained from the EPR spectrum and Matumura's plot [26]. It corresponds to an ionicity of $94 \%$, where, as in the case of white dolomite, " $A$ " with a value of $9.15 \mathrm{mT}$ gives an ionicity of $91 \%$. Also the approximate value of hyperfine constant $(A)$ is calculated for both dolomites by using covalency $(C)$ using the following equation (see $[27,28]$ ):

$$
A_{\text {iso }}=(2.04 C-104.5) 10^{-4} \mathrm{~cm}^{-1} \text {. }
$$

The value obtained is $92 \times 10^{-4} \mathrm{~cm}^{-1}$ for green dolomite, whereas for the white dolomite it is $91 \times 10^{-4} \mathrm{~cm}^{-1}$. This calculated value agrees well with the observed hyperfine constant for both samples indicating ionic character for Mn$\mathrm{O}$ bond in the mineral under study. The number of ligands around $\mathrm{Mn}(\mathrm{II})$ ion is estimated using the covalency [27] equation for $C$

$$
C=\frac{1}{n}\left[1-0.16\left(X_{p}-X_{q}\right)-0.035\left(X_{p}-X_{q}\right)^{2}\right] .
$$

Here $X_{p}$ and $X_{q}$ represent electronagativities of metal and ligand. Assuming $X_{p}=X_{\mathrm{Mn}}=1.4$ and $X_{q}=X_{O}=3.5$, the number of ligands $(n)$ obtained are 20. This suggests that $\mathrm{Mn}$ (II) may be surrounded by four $\mathrm{CO}_{3}^{2-}$ and two oxygens. Further the $g$ value for the hyperfine splitting is indicative of the nature of bonding. If the $g$ value shows negative shift with respect to free electron $g$ value of 2.0023 , the bonding is ionic and conversely, if the shift is positive, the bonding is more covalent in nature [29]. In the present work, from the observed negative values of 0.0103 for white dolomite and that of -0.0093 for green dolomite, it is apparent that the $\mathrm{Mn}(\mathrm{II})$ is in an ionic environment. EPR spectrum of white dolomite (Figure 2(b)) reveals that in between first and second manganese hyperfine resonance lines a very weak sharp peak at (319.2 $\mathrm{mT})$ having a $g$ value 2.1019 is observed.

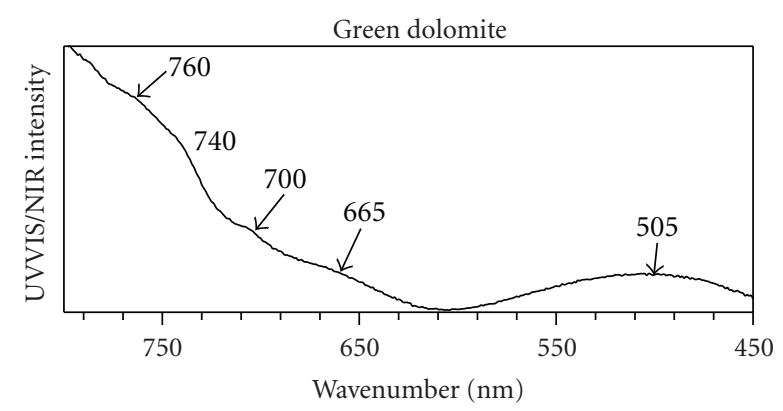

FIGURE 3: Optical absorption spectrum of green dolomite at room temperature.

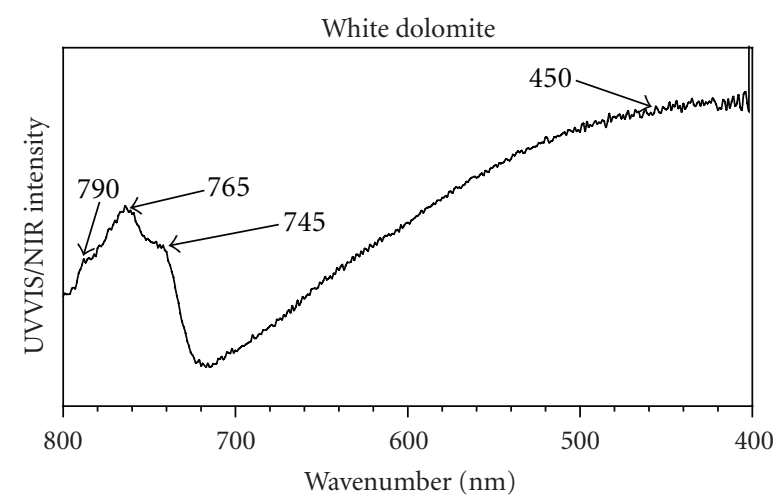

Figure 4: Optical absorption spectrum of white dolomite at room temperature.

This can be ascribed to a radical such as $\mathrm{CO}_{3}^{2-}$ or $\mathrm{NO}_{3}^{2-}$. The absence of any super hyperfine structure in the radical suggests that the radical may be $\mathrm{CO}_{3}^{2-}[11]$.

\subsection{Optical Absorption Spectral Analysis}

Ferric iron, Fe(III), has the electronic configuration Ar $\left(3 d^{5}\right)$ with a half filled $d$-shell having one unpaired electron in each of the orbitals. Hence ground state configuration is $t_{2 g}^{3} e_{g}^{2}$. The free ion levels of $\mathrm{Fe}(\mathrm{III})$, in the order of increase in energy, are ${ }^{6} \mathrm{~S},{ }^{4} \mathrm{G},{ }^{4} \mathrm{P},{ }^{4} \mathrm{D},{ }^{4} \mathrm{~F}$. The energy levels for $\mathrm{Fe}(\mathrm{III})$ in an octahedral environment are ${ }^{6} \mathrm{~A}_{1 \mathrm{~g}}\left({ }^{6} \mathrm{~S}\right)$, ${ }^{4} \mathrm{~T}_{1 \mathrm{~g}}\left({ }^{4} \mathrm{G}\right),{ }^{4} \mathrm{~T}_{2 \mathrm{~g}}\left({ }^{4} \mathrm{G}\right),{ }^{4} \mathrm{~A}_{1 \mathrm{~g}}(\mathrm{G})-{ }^{4} \mathrm{E}_{\mathrm{g}}\left({ }^{4} \mathrm{G}\right),{ }^{4} \mathrm{~T}_{2 \mathrm{~g}}\left({ }^{4} \mathrm{D}\right)$, and ${ }^{4} \mathrm{E}_{\mathrm{g}}\left({ }^{4} \mathrm{D}\right)$. The ${ }^{4} A_{1 g}(G)-{ }^{4} E_{g}\left({ }^{4} G\right)$ and ${ }^{4} E_{g}\left({ }^{4} D\right)$ levels have relatively less influence compared to other levels by crystal field. It means that the relative sharp levels can be expected in the absorption spectrum which is the criterion for assignment of levels for Fe(III) ion. Since all the excited states of Fe(III) ion will be either quartets or doublets, the optical absorption spectra of $\mathrm{Fe}$ (III) ions will have only spin forbidden $\mathrm{d}$-d transitions. These occur from the ground state ${ }^{6} \mathrm{~A}_{1 \mathrm{~g}}(\mathrm{~S})$ to the excited states ${ }^{4} \mathrm{~T}_{1 \mathrm{~g}}(\mathrm{G}),{ }^{4} \mathrm{~T}_{2 \mathrm{~g}}(\mathrm{G}),{ }^{4} \mathrm{~A}_{1 \mathrm{~g}}(\mathrm{G}),{ }^{4} \mathrm{E}_{\mathrm{g}}(\mathrm{G}),{ }^{2} \mathrm{~T}_{1 \mathrm{~g}}(\mathrm{D})$, ${ }^{4} \mathrm{E}_{\mathrm{g}}(\mathrm{D})$, and ${ }^{4} \mathrm{~T}_{1 \mathrm{~g}}(\mathrm{P})$ of regular octahedron [30].

Optical absorption spectrum of green dolomite recorded in the mull form at RT in the range of 200-1200 nm is shown in Figure 3 and that of white dolomite is shown in Figure 4. The green dolomite spectrum shows energies at $13160 \mathrm{~cm}^{-1}$ 
TABLE 2: Band headed data with assignments for Fe(III) in natural dolomite mineral.

\begin{tabular}{|c|c|c|c|c|c|c|}
\hline & mite oreen & & & mite white & & \\
\hline$D q=900$ & $605 C=2$ & $\mathrm{n}^{-1}$ & $D q=900$ & $600 C=26$ & $n^{-1}$ & \\
\hline & $90 \mathrm{~cm}^{-1}$ & & & $90 \mathrm{~cm}^{-1}$ & & Transition from ${ }^{6} \mathrm{~A}_{\mathrm{lg}}$ \\
\hline Wave length (nm) & Waven & $\mathrm{r}\left(\mathrm{cm}^{-1}\right)$ & Wave length (nm) & Waven & $\mathrm{r}\left(\mathrm{cm}^{-1}\right)$ & \\
\hline & Observed & Calculated & & Observed & Calculated & \\
\hline & & & 790 & 12660 & & \\
\hline 760 & 13160 & 13161 & 765 & 13070 & 13087 & \\
\hline 740 & 13515 & & 745 & 13425 & & ${ }^{4} \mathrm{~T}_{\mathrm{lg}}(\mathrm{G})$ \\
\hline 700 & 14285 & & - & - & & \\
\hline 665 & 14995 & 16951 & - & - & 16852 & ${ }^{4} \mathrm{~T}_{2 \mathrm{~g}}(\mathrm{G})$ \\
\hline 505 & 19800 & 20813 & 450 & 22220 & 20739 & ${ }^{4} \mathrm{E}_{\mathrm{g}}(\mathrm{G})$ \\
\hline & & & & & & ${ }^{4} \mathrm{~A}_{\mathrm{lg}}(\mathrm{G})$ \\
\hline
\end{tabular}

$(760 \mathrm{~nm}), \quad 13515 \mathrm{~cm}^{-1} \quad(740 \mathrm{~nm}) .14285 \mathrm{~cm}^{-1} \quad(700 \mathrm{~nm})$, $14995 \mathrm{~cm}^{-1}(665 \mathrm{~nm})$, and $19800 \mathrm{~cm}^{-1}(505 \mathrm{~nm}) \mathrm{cm}^{-1}$ in the UV-Vis region whereas white dolomite spectrum shows energies at $12660 \mathrm{~cm}^{-1}(790 \mathrm{~nm}), 13070 \mathrm{~cm}^{-1}(765 \mathrm{~nm})$, $13425 \mathrm{~cm}^{-1}(745 \mathrm{~nm}), 22220 \mathrm{~cm}^{-1}(450 \mathrm{~nm}) \mathrm{cm}^{-1}$ in the UV-Vis region. In green dolomite, the band observed at $13515 \mathrm{~cm}^{-1}$ with split component on left side at $13160 \mathrm{~cm}^{-1}$ is assigned to the transition ${ }^{6} \mathrm{~A}_{1 \mathrm{~g}}(\mathrm{~S}) \rightarrow{ }^{4} \mathrm{~T}_{1 \mathrm{~g}}(\mathrm{G})$ whereas the band at $14995 \mathrm{~cm}^{-1}$ is assigned to ${ }^{4} \mathrm{~T}_{2 \mathrm{~g}}(\mathrm{G})$ transition. The third band visible around $19800 \mathrm{~cm}^{-1}$ is assigned to ${ }^{4} \mathrm{~A}_{\mathrm{lg}}(\mathrm{G}),{ }^{4} \mathrm{E}_{\mathrm{g}}(\mathrm{G})$ transition. These bands are characteristic of $\mathrm{Fe}$ (III) ion in octahedral symmetry in the mineral. This is also further supported by EPR studies. Using Tree's polarization term $\alpha=90 \mathrm{~cm}^{-1}$ [26], the energy matrices of the $\mathrm{d}^{5}$ configuration are solved for various $B, C$, and $D q$ values. The evaluated parameters are presented in Table 2. A comparison is also made between the calculated and observed energies of the bands and these are presented in Table 2. The sharp band observed in green dolomite at $14285 \mathrm{~cm}^{-1}$ may be due to $\mathrm{Mn}(\mathrm{II})$. The very sharp band observed at $13070 \mathrm{~cm}^{-1}$ in white dolomite with split component on either side (at 12660 and $13425 \mathrm{~cm}^{-1}$ with average of $13043 \mathrm{~cm}^{-1}$ ) is assigned to the transition ${ }^{6} \mathrm{~A}_{1 \mathrm{~g}}(\mathrm{~S}) \rightarrow{ }^{4} \mathrm{~T}_{1 \mathrm{~g}}(\mathrm{G})$. Similar assignment is also made in green dolomite. The intensity of the band in white dolomite is large when compared to green dolomite. Further in white dolomite the band visible around $16000 \mathrm{~cm}^{-1}$ due to the transition of ${ }^{6} \mathrm{~A}_{1 \mathrm{~g}}(\mathrm{~S}) \rightarrow{ }^{4} \mathrm{~T}_{2 \mathrm{~g}}(\mathrm{G})$ is not seen. This may be due to low concentration of iron in the mineral. The third band at $22220 \mathrm{~cm}^{-1}$ is assigned to ${ }^{4} \mathrm{~A}_{\mathrm{lg}}(\mathrm{G}),{ }^{4} \mathrm{E}_{\mathrm{g}}(\mathrm{G})$ transition. These bands are characteristic of $\mathrm{Fe}$ (III) ion in octahedral symmetry in the mineral. This is also further supported by EPR studies. Using Tree's polarization term $\alpha=$ $90 \mathrm{~cm}^{-1}$ [31], the energy matrices of the $\mathrm{d}^{5}$ configuration are solved for various $B, C$, and $D q$ values. A comparison is also made between the calculated and observed energies of the bands and these are presented in Table 2. These results agree well with the reported values of different dolomite minerals of Indian origin [12].

\subsection{Near Infrared Spectroscopy}

Water has three fundamental modes. They are symmetric $\mathrm{OH}$ stretch $\left(\nu_{1}\right), \mathrm{H}-\mathrm{O}-\mathrm{H}$ bending mode $\left(\nu_{2}\right)$, and asymmetric $\mathrm{OH}$ stretch $\left(\nu_{3}\right)$. In solid phase, these modes appear at $3220\left(\nu_{3}\right), 1620\left(\nu_{2}\right)$, and $3400\left(\nu_{1}\right) \mathrm{cm}^{-1}$ [32]. The shifting of $\nu_{1}$ and $\nu_{3}$ towards lower frequency and $\nu_{2}$ towards higher frequency is due to hydrogen bonding [33].

\subsubsection{The 11500 to $5500 \mathrm{~cm}^{-1}$ Spectral Region}

Figure 5 shows near infrared spectrum of dolomite mineral from $11500-5500 \mathrm{~cm}^{-1}$ region. The near-IR spectral regions may be conveniently divided as follows: the high wave number region $>7500 \mathrm{~cm}^{-1}$ : in this region, electronic bands due to the characteristic of $\mathrm{Fe}^{2+}$ and $\mathrm{Fe}^{3+}$ ions are observed. The two bands observed in green dolomite at 9286 and $8581 \mathrm{~cm}^{-1}$ are broad and are of very low intensity which are assigned to the two components of the transition ${ }^{2} \mathrm{~T}_{2 \mathrm{~g}} \rightarrow$ ${ }^{5} \mathrm{E}_{\mathrm{g}}$. This may be due to trace of Fe(II) present in the sample. The average of these bands $8934 \mathrm{~cm}^{-1}$ is taken as $10 D q$. But in white dolomite no Fe(II) bands are noticed.

The high wave number region between $7200 \mathrm{~cm}^{-1}$ and $6300 \mathrm{~cm}^{-1}$ is attributed to the first overtone of the fundamental hydroxyl stretching mode. The very sharp group of bands at 7127 and split components on either side at 7237 and $7036 \mathrm{~cm}^{-1}$ with high intensity are due to $2 v_{3}$, the asymmetric $\mathrm{OH}$ stretch in the green dolomite. Exactly the similar very sharp group of bands observed at $7154 \mathrm{~cm}^{-1}$ with components at 7232, 7173, and $6920 \mathrm{~cm}^{-1}$ with maximum intensity are assigned to the same $2 v_{3}$ asymmetric $\mathrm{OH}$ stretch in the white dolomite.

\subsubsection{The 5500 to $4000 \mathrm{~cm}^{-1}$ Spectral Region}

The spectral region from $5500 \mathrm{~cm}^{-1}$ to $4000 \mathrm{~cm}^{-1}$ is made up of two parts: the $4000-4500 \mathrm{~cm}^{-1}$ region in which $\mathrm{OH}$ combination bands are found and $4500-5500 \mathrm{~cm}^{-1}$ region 

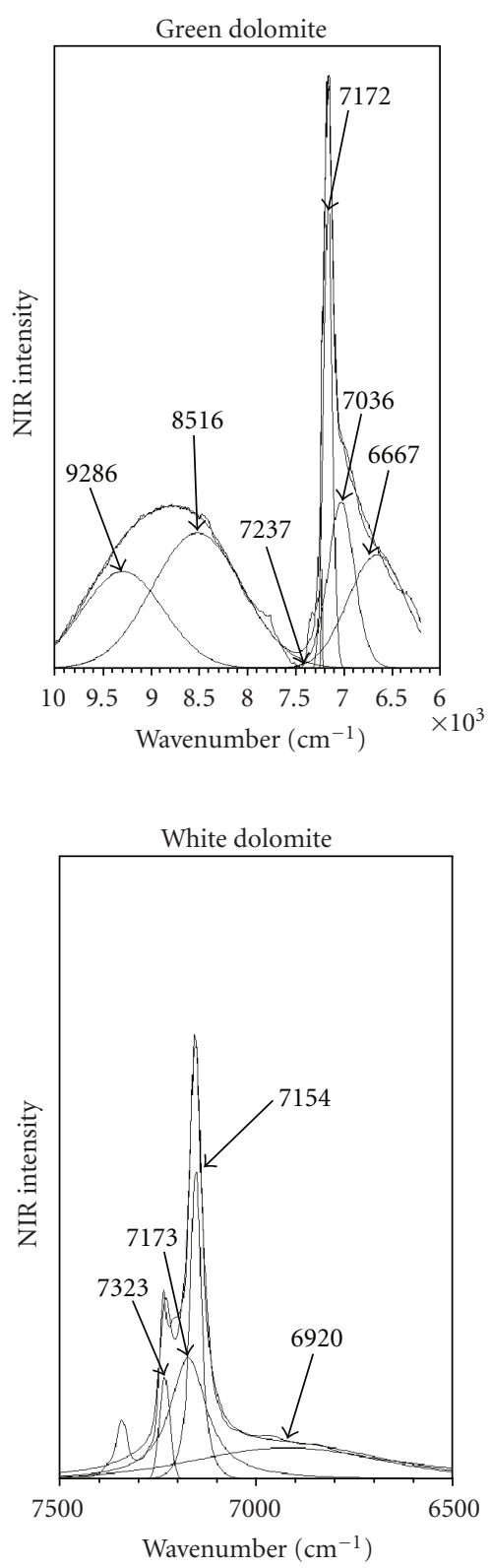

FIGURE 5: NIR spectrum of dolomite at room temperature from $11000-5500 \mathrm{~cm}^{-1}$.

in which water combination bands are observed. Figure 6 shows a profile of bands at $4300 \mathrm{~cm}^{-1}$ with high intensity and with components on either side at 4397 and $4123 \mathrm{~cm}^{-1}$. These bands in green dolomite are assigned to the water $\mathrm{OH}$ combination. In white dolomite, similar bands are observed with less intensity at $4293 \mathrm{~cm}^{-1}$ with a shoulder at $4388 \mathrm{~cm}^{-1}$ which may be attributed to the water $\mathrm{OH}$ combination. The intense band observed at $5083 \mathrm{~cm}^{-1}$ in green dolomite is attributed to the water $\mathrm{OH}$ overtone. The same band with very low intensity observed at $5078 \mathrm{~cm}^{-1}$ in white dolomite is assigned to the water $\mathrm{OH}$ overtone. In general, the NIR bands observed for white dolomite are less intense when compared to green dolomite which indicates that water is more in green dolomite than that present in white dolomite.
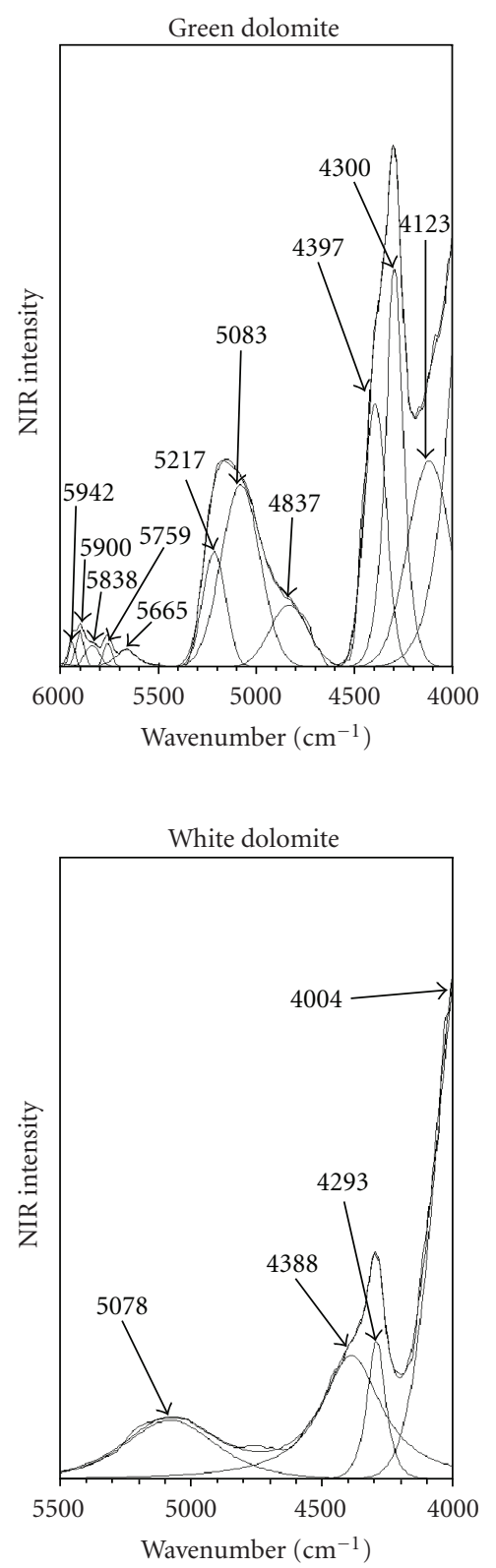

FIGURE 6: NIR spectrum of dolomite at room temperature from $5500-4000 \mathrm{~cm}^{-1}$.

\section{Conclusion}

EPR results indicate that $\mathrm{Fe}(\mathrm{III})$ and $\mathrm{Mn}(\mathrm{II})$ are present in the mineral in distorted octahedral environment. The $g$ value of 4.34 in green dolomite and that of 4.20 in white dolomite are ascribed to $\mathrm{Fe}$ (III). This supports that the sample contains isolated $\mathrm{Fe}$ (III) ions in the lattice of the dolomite mineral In both dolomites, the values of $g, A$, and $D$ in the spectra are $g=1.992 \pm 0.015, A=9.15 \pm 0.43 \mathrm{mT}$, and $D=34.45 \pm$ $0.36 \mathrm{mT}$ (white dolomite) and $g=1.993 \pm 0.017, A=9.35 \pm$ $0.43 \mathrm{mT}$, and $D=34.25 \pm 0.35 \mathrm{mT}$, respectively, and they are due to $\mathrm{Mn}$ (II) indicating distorted octahedral environment in the mineral. These results suggest that $\mathrm{Mn}$ (II) is replaced either by $\mathrm{Ca}$ or $\mathrm{Mg}$ site. Also white dolomite shows a free 
radical at $g=2.1019$ which is ascribed to $\mathrm{CO}_{3}^{2-}$ which may be a geological indicator. Thus EPR is a very sensitive technique for the magnetic analysis of paramagnetic components in diamagnetic (carbonate) minerals.

The optical absorption studies indicate that Fe(III) ion is present in major quantity in both dolomites whereas $\mathrm{Fe}$ (II) is in traces in the green dolomite mineral. These ions are also present in distorted octahedral environment. Green color of the mineral is due to $\mathrm{Fe}(\mathrm{II})$ which is evident from the optical absorption spectrum.

Near-infrared spectrum is due to overtones and combinations of water molecules. Also green dolomite sample contains more lattice water than the white dolomite mineral.

\section{Acknowledgment}

The authors wish to express their sincere thanks to Professor P. S. Rao, Department of Chemistry, Pondicherry University, Puducherry, India, for providing EPR instrumental facility.

\section{References}

[1] The Mineral Dolomite, http://www.minerals-n-more.com/.

[2] The Dolomite group of Minerals, http://www.galleries.com/.

[3] R. J. Reeder and W. A. Dollase, "Structural variation in the dolomite-ankerite solid-solution series: an X-ray, Mossbauer, and TEM study," American Mineralogist, vol. 74, no. 9-10, pp. 1159-1167, 1989.

[4] R. J. Reeder and H. R. Wenk, "Structure refinements of some thermally disordered dolomites," American Mineralogist, vol. 68, no. 7-8, pp. 769-776, 1983.

[5] J. W. Anthony, R. A. Bideaux, K. W. Bladh, and N. C. Nichols, Handbook of Mineralogy, vol. 5, Mineral Data, Tucson, Ariz, USA, 2003.

[6] W. A. Dollase and R. J. Reeder, "Crystal structure refinement of huntite, $\mathrm{CaMg}_{3}\left(\mathrm{CO}_{3}\right)_{4}$, with X-ray powder data," American Mineralogist, vol. 71, no. 1-2, pp. 163-166, 1986.

[7] D. E. Miser, J. Steven Swinnea, and H. Steinfink, "TEM observations and X-ray crystal-structure refinement of a twinned dolomite with a modulated microstructure," American Mineralogist, vol. 72, no. 1-2, pp. 188-193, 1987.

[8] F. Prissok and G. Lehmann, "An EPR study of $\mathrm{Mn}^{2+}$ and $\mathrm{Fe}^{3+}$ in dolomites," Physics and Chemistry of Minerals, vol. 13, no. 5, pp. 331-336, 1986.

[9] J. Granwehr, P. G. Weidler, and A. U. Gehring, "The fate of structure-bound $\mathrm{Mn}^{2+}$ during the decomposition of dolomite and in the resulting conversion products: an EPR study," American Mineralogist, vol. 89, no. 5-6, pp. 785-789, 2004.

[10] N. P. Crook, S. R. Hoon, K. G. Taylor, and C. T. Perry, "Electron spin resonance as a high sensitivity technique for environmental magnetism: determination of contamination in carbonate sediments," Geophysical Journal International, vol. 149, no. 2, pp. 328-337, 2002.

[11] R. W. A. Franco, F. Pelegrini, and A. M. Rossi, "Identification and valuation of paramagnetic radicals in natural dolomites as an indicator of geological events," Physics and Chemistry of Minerals, vol. 30, no. 1, pp. 39-43, 2003.

[12] S. Gunasekaran and G. Anbalagan, "Optical absorption and EPR studies on some natural carbonate minerals," Spectrochimica Acta Part A, vol. 69, no. 2, pp. 383-390, 2008.
[13] M. C. R. Symons, Chemical and Biochemical Aspects of Electron Spin Resonance Spectroscopy, John Wiley \& Sons, New York, NY, USA, 1978.

[14] D. E. De Vos, B. M. Weckhuysen, and T. Bein, "ESR fine structure of manganese ions in zeolite A detects strong variations of the coordination environment," Journal of the American Chemical Society, vol. 118, no. 40, pp. 9615-9622, 1996.

[15] The Good Earth, Udaipur, Rajasthan, India, http://www.thegoodearth.co.in/.

[16] Famous Minerals and Chemicals Private Limited.

[17] Mineral data Publishing Version I, (c) 2001-2005.

[18] S. J. Hattan, T. M. Laue, and N. D. Chasteen, "Purification and characterization of a novel calcium-binding protein from the extrapallial fluid of the mollusc, Mytilus edulis," The Journal of Biological Chemistry, vol. 276, no. 6, pp. 4461-4468, 2001.

[19] A. Abragam and B. Bleancy, Electron Paramagnetic Resonance of Transtion Ions, Oxford University Press, Oxford, UK, 1970.

[20] B. Bleaney and R. S. Rubins, "Explanation of some 'forbidden' transitions in paramagnetic resonance," Proceedings of the Physical Society, vol. 77, no. 1, pp. 103-112, 1961.

[21] J. M. Nedelec, M. Bouazaoui, and S. Turrell, "Densification of $\mathrm{Mn}^{2+}$ doped monolithic silica xerogels: an electron spin resonance study," Physics and Chemistry of Glasses, vol. 40, no. 5, pp. 264-268, 1999.

[22] S. Lakshmi Reddy, N. C. Gangi Reddy, G. Siva Reddy, B. Jagannatha Reddy, and R. L. Frost, "Characterization of clinohumite by selected spectroscopic methods," Spectrochimica Acta Part A, vol. 65, no. 3-4, pp. 684-688, 2006.

[23] S. Lakshmi Reddy, K. N. M. Reddy, G. Siva Reddy, B. J. Reddy, R. L. Frost, and T. Endo, "Electron paramagnetic resonance, optical absorption, IR and Raman spectral studies on pelecypod shell," Spectrochimica Acta Part A, vol. 69, no. 2, pp. 503-508, 2008.

[24] C. P. Lakshmi Prasuna, K. V. Narasimhulu, N. O. Gopal, J. Lakshmana Rao, and T. V. R. K. Rao, "The microstructures of biomineralized surfaces: a spectroscopic study on the exoskeletons of fresh water (Apple) snail, Pila globosa," Spectrochimica Acta Part A, vol. 60, no. 10, pp. 2305-2314, 2004.

[25] P. Schindler and S. Ghose, "Electron paramagnetic resonance of $\mathrm{Mn}^{2+}$ in dolomite, and magnesite; and $\mathrm{Mn}^{2+}$ distribution in dolomites," The American Mineralogist, vol. 55, no. 11-12, pp. 1889-1896, 1970.

[26] O. Matumura, "Electron spin resonance of Mn-activated phosphors," Journal of the Physical Society of Japan, vol. 14, no. 1, p. $108,1959$.

[27] E. Šimánek and K. A. Müller, "Covalency and hyperfine structure constant A of iron group impurities in crystals," Journal of Physics and Chemistry of Solids, vol. 31, no. 5, pp. 1027-1040, 1970.

[28] A. M. F. Benial, V. Ramakrishnan, and R. Murugesan, "Single crystal electron paramagnetic resonance study of $\mathrm{Mn}(\mathrm{II})$ doped $\mathrm{Zn}\left(\mathrm{C}_{5} \mathrm{H}_{5} \mathrm{NO}\right)_{6}\left(\mathrm{BF}_{4}\right)_{2}$ : probe into site symmetry," Spectrochimica Acta Part A, vol. 55, no. 13, pp. 2573-2577, 1999.

[29] J. S. van Wieringen, "Paramagnetic resonance of divalent manganese incorporated in various lattices," Discussions of the Faraday Society, vol. 19, pp. 118-126, 1955.

[30] J. Wang, S. Wang, and Q. Su, "The role of excess $\mathrm{Zn}^{2+}$ ions in improvement of red long lasting phosphorescence (LLP) performance of $\beta-\mathrm{Zn}_{3}\left(\mathrm{PO}_{4}\right)_{2}$ :Mn phosphor," Journal of Solid State Chemistry, vol. 177, no. 3, pp. 895-900, 2004.

[31] W. Low and G. Rosengarten, "The optical spectrum and ground-state splitting of $\mathrm{Mn}^{2+}$ and $\mathrm{Fe}^{3+}$ lons in the crystal field 
of cubic symmetry," Journal of Molecular Spectroscopy, vol. 12, no. 4, pp. 319-346, 1964.

[32] K. Nakamoto, Infrared Spectra of Inorganic and Coordination Compounds, John Wiley \& Sons, New York, NY, USA, 1970.

[33] G. R. Hunt and J. W. Salisbury, "Visible and near ir spectra of minerals and rocks-I: silicate minerals," Modern Geology, vol. 1, pp. 283-300, 1970. 

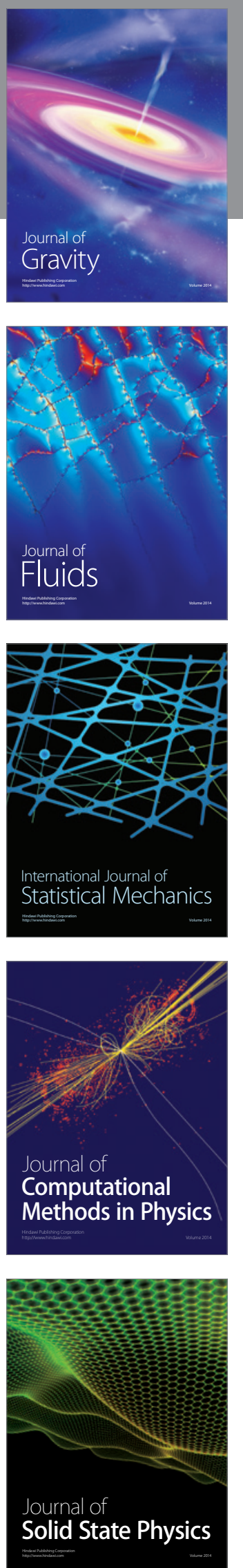

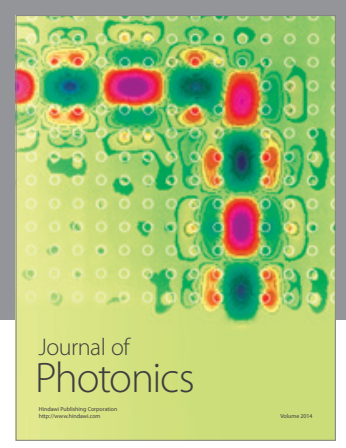

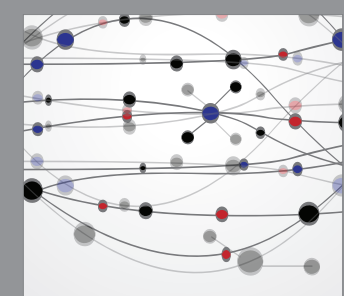

The Scientific World Journal
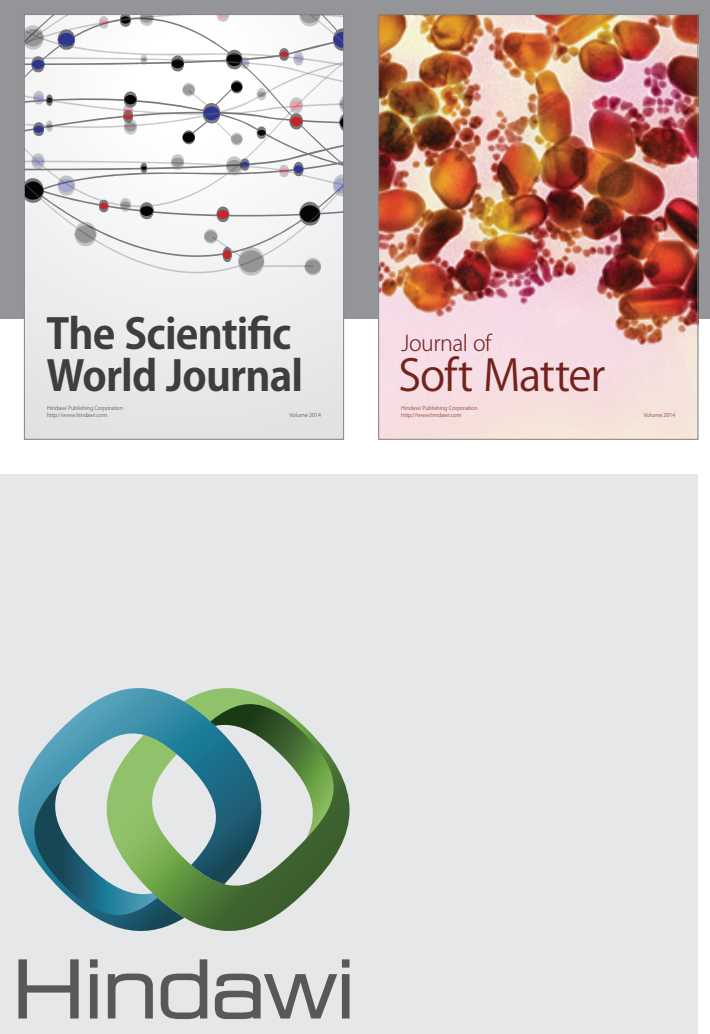

Submit your manuscripts at

http://www.hindawi.com
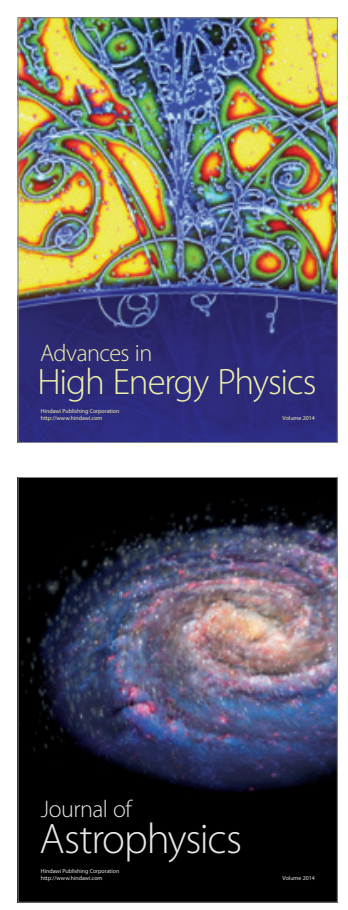
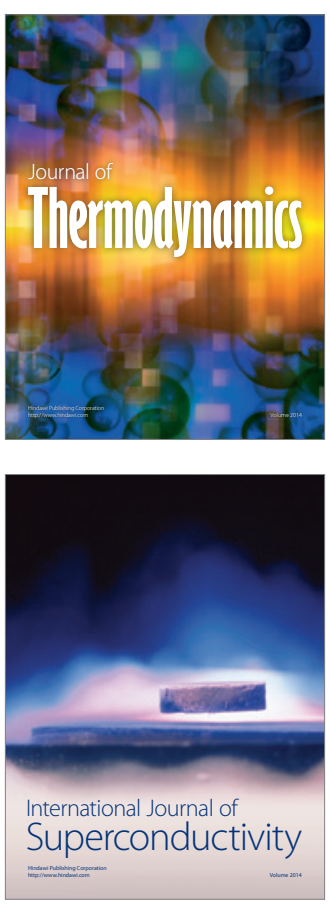
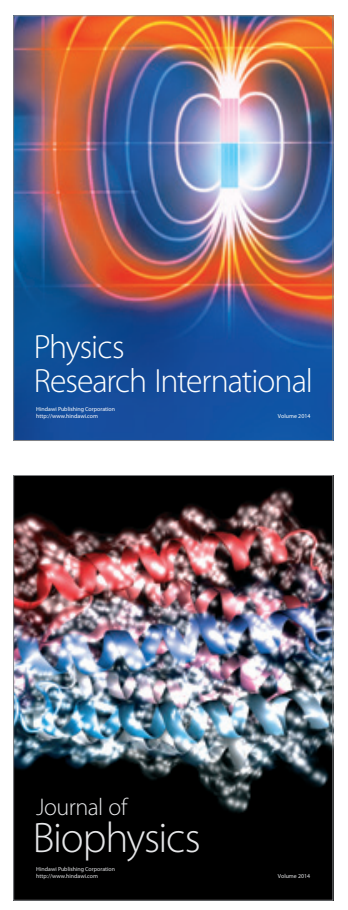
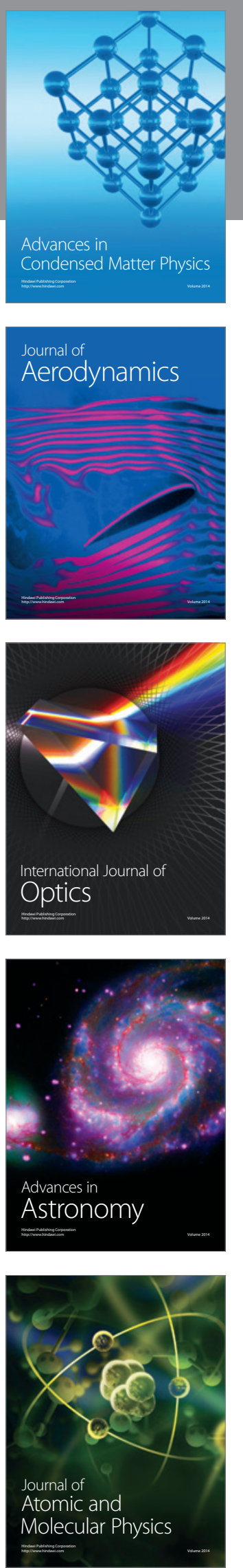